\title{
Public Pedagogy at the Geelong Powerhouse: Intercultural Understandings through Street Art within the Contact Zone
}

\author{
Belinda MacGill
}

South Australia University

\begin{abstract}
This paper wrestles with the possibilities of a new representational field emerging through street art in Australia. It highlights the intersections between public space, curated space, street art and representations of Indigenous culture in order to contribute to conversations concerning public pedagogy. The Geelong Powerhouse site is used to examine how the public engages with Indigenous political narratives in contact zones. This is juxtaposed with museums and text mediated sites in order to examine the possibility of an emerging visual and digital literacy in Australia. Considerations of how context shapes meanings for audiences are explored with the aim of moving beyond the tensions that set limits on dialogic intercultural understandings of intersectionality.
\end{abstract}

\section{Keywords}

intercultural understanding, public pedagogy, street art 
This paper brings the concept of the 'contact zone' (Boast 2011; Pratt 1997) into conjunction with recent research in public pedagogy. The aim is to explore the limits and possibilities of intercultural understanding through street art. The contact zone is a concept used in Education, Indigenous studies and Cultural studies to describe the space of encounter of difference that shapes the experience of an individual and their subsequent learning within that space. This paper examines contact zones, such as the Geelong Powerhouse; a dilapidated building covered with street art, as well as, museums and Instagram. These contact zones offer a diverse range of learning encounters as a result of their distinctive affordances. Explorations of curated and semi curated contact spaces are considered in relation to how knowledge is assembled depending on contexts.

The paper begins with an exploration of public pedagogy through a personal encounter with the Street Art of Rone, Adnate and Urbanmonk (JMC, Josh McCrimmon) at the Geelong Powerhouse. Coupled with the subsequent following of these images on Instagram and the possibilities of learning within digitally mediated contact zones. Following on from the works of Giroux (2016), Burdick and Sandlin (2013) and Manovic (2016) questions are raised regarding 'the role of educational agents in stimulating or unsettling what appear to be 'spontaneous' learning processes in relation to living with difference' (Schuermans et.al 2012, p. 280). The affordances of digital and visual literacy are considered in relation to new fields of intercultural understandings through text-media representations of Indigenous issues throughout this paper.

\section{Contact Zones}

Contact zones (Pratt 1997) operate as metaphoric spaces that provide opportunities for inter-cultural understanding. Contact zones have been cited as educative spaces within schools and universities to explore divergent standpoints. Pratt's (1997) theorisation of contact zones is positioned to be a decolonising space. These spaces offer opportunities to assemble new understanding of intersectionality through dialogic exchange. Arguably, contact zones can be any site where there is interaction and dialogue. The encounter within the contact zone shapes the learning experience due to the metaphors used in dialogic exchange that are 'governed by a single set of rules or norms shared by all participants' (Pratt 1997, pp. 68-9). Contact zones provide a space for public pedagogy to emerge, but the learning experience is contingent on context, location and audience.

\section{Public Pedagogy: The Geelong Powerhouse, Street Art and Postcolonial Receptivity within Contact Zones}

Public pedagogy (Biesta 2012; Schuermans et.al 2012) is a well-explored field, but there are variations in its definition. One of Burdick and Sandlin's (2013) frame for public pedagogy 'centres on a concern with relation and the dimensions of subjective experience through an emphasis on embodiment, affect, and the psychic dimensions of the teaching and learning encounter' (Burdick, Sandlin \& O'Malley 2013, p. 55). The impetus for this paper was the embodiment and affect of a learning encounter at the Geelong Powerhouse.

I began exploring the possibilities of the Geelong Powerhouse as a site of public pedagogy as a result of my subjective experience at the site. It was an unguided experimental learning encounter (Gaoralnick, et.al. 2012, p. 419). The semi-curated space of Geelong Powerhouse enabled a kinaesthetic experience, as there was no curatorial voice guiding me as the audience, but instead the space offered me the freedom to photograph any image without surveillance; it was unleashed voyeurism. I had agency to capture any image, but was drawn to the paste- 
ups of Indigenous political narratives by Urbanmonk. (See the paste up on the pillar called Sorry-Play that Card Again (by Mini Graff) and the two paste-ups of Aboriginal children on the back wall below called Great Antidote to the Inner Critic. Who is Always Whispering Sweet (you're) Nothings in my Inner Ear).

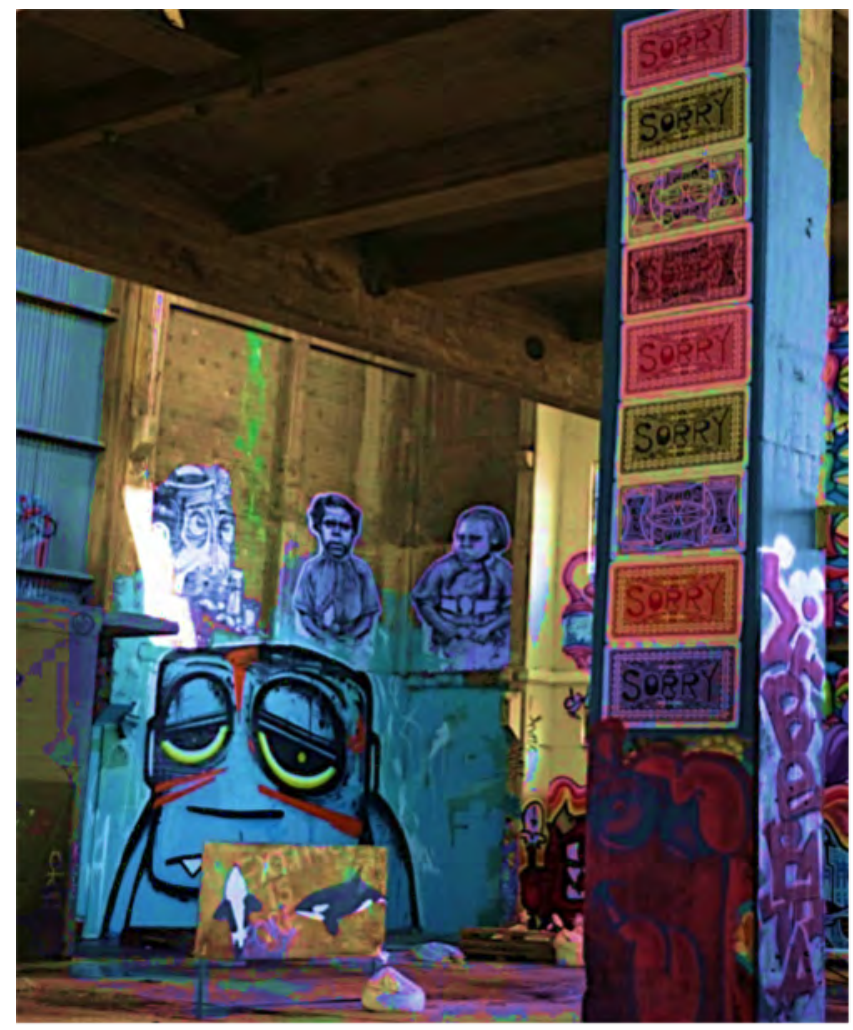

Figure 1: Great Antidote to the Inner Critic. Who is Always Whispering Sweet (you're) Nothings in my Inner Ear by Urbanmonk, and Sorry-Play that Card Again by Mini Graff. Photo by author Oct 2015.

It was the first time I had seen these types of representations within a constellation of mixed texts. I read these texts as political protests, but they were not presented as instructive, instead they appeared as purposeful protests with the intention of raising public consciousness. This is where:

The political and the educational dimension come together in the idea of 'public pedagogy'. Although much work on public pedagogy has focused on the analysis of how media, culture and society function as educative forces... [T] he idea of public pedagogy can also be understood in a more programmatic and more political way, which is as an educational intervention enacted in the interest of the public quality of spaces and places and the public quality of human togetherness more generally (Biesta 2012, p. 684).

In this sense the public pedagogy in creative contact zones, such as the Geelong Powerhouse enhance a postcolonial receptivity (Bignall \& MacGill 2016) to Indigenous political narratives. As Goralnik et al. state the experimental domain of knowledge occurs when learners encounter a subject, person, place, or thing personally and directly. There are kinaesthetic, cognitive, and emotional connections we make when learning becomes personally experienced with multiple senses' (2012, p. 419). Learning is a constellation of events where we build understanding through assembling knowledge that is shaped by the particulars of the lens presented. In this case, Sorry (Mini Graff) and Great Anecdote (Urbanmonk) re-po- 
sitions the debate of structural inequality through his paste-ups and thereby sets a tone for receptivity. Nik Kompridis states:

receptivity as a form of normative responsiveness that is both spontaneous and reflective, which is to say a form of agency through which we are responsive to something or someone in an attitude of answerability. The spontaneous moment of receptivity is what we commonly refer to when we speak of openness, openness to that which is unfamiliar or unsettling, a spontaneous readiness to follow a line of flight or descent. Conceiving of receptivity in this way allows us to think of our epistemic and normative agency, our mindedness, if you like, as involving and requiring exposure to human vulnerability - the vulnerability of a being that can be marked, struck, impressed by experienced reality, by what and whom it encounters in the world. It involves and requires a willingness to risk self-dispossession, and thus it is not so much about becoming open as it is about becoming unclosed to something or someone (Kompridis 2013, p. 20; see also 2011; 2006).

Arguably, this street art enhances receptivity as a public pedagogy. The context of the Geelong Powerhouse provides the space for openness as it invites the audience to a 'mindedness' about 'human vulnerability'. Howitt (2011) argues public pedagogy is not neutral, but is hinged on location, context and use of spatial metaphors that are inclusive or exclusive. Askin and Pain (2011) state that 'spaces of interaction' offer possibilities for 'transformative social relations'. The Geelong Powerhouse is a contact zone that offers interesting possibilities for learning through offering intercultural understanding of Indigneous political issues as outlined below.

\section{Contact Zone 1: Geelong Powerhouse}

Geelong Powerhouse is a 'vibrant arts precinct' and 'Australia's largest indoor legal space to create ephemeral street art' (Geelong Powerhouse). The Geelong Powerhouse is an impressive monolithic space overlooking Corio Bay. The entrance to the site parallels the magnificence of a mansion estate, but flavoured with industrial architecture and colourful street art that vibrates with creative life. It is a site for opportunity and agency for street artists. The space provides legitimation of the genre as an art.

The gates are open to a paying public, including tourists, cultural theorists, youth and street artists. Walking around the building before entering I recognised Rones' photorealist piece aptly titled Broken window theory (fig. 3). This astonishing work captures a woman's forlorn face on the façade of the abandoned factory and he uses the shattered panes of glass to create an etched dissipating face. Rone's clever title Broken Window is from the theory espoused in criminology that broken windows induce crime.

Moving into the building and wandering around the site, avoiding the drips from the ceiling and side stepping the seemingly septic puddles, there was a sense of freedom. People physically engaged in the space, spoke loudly, took photos and meandered randomly. This was in contrast to a viewing experience at a gallery or a museum where the viewer is under surveillance by the guards and moves furtively throughout the space. The physical space of the Geelong Powerhouse offered a contact zone to engage with the texts on the wall, and to a degree, own them through capturing selected images.

The texts representing Indigenous political counter-narratives included works by Urbanmonk, and @jmunz549 and @loweairbrush. These works sit alongside a range of stylised, sexualised, politicised and inane texts, however these appeared as 'active political interventions' (Schuermans et al. 2012, p. 677). Do these images that are juxtaposed on the walls provide a counter-narrative to the omission of Indigenous themes in the public space, apart 


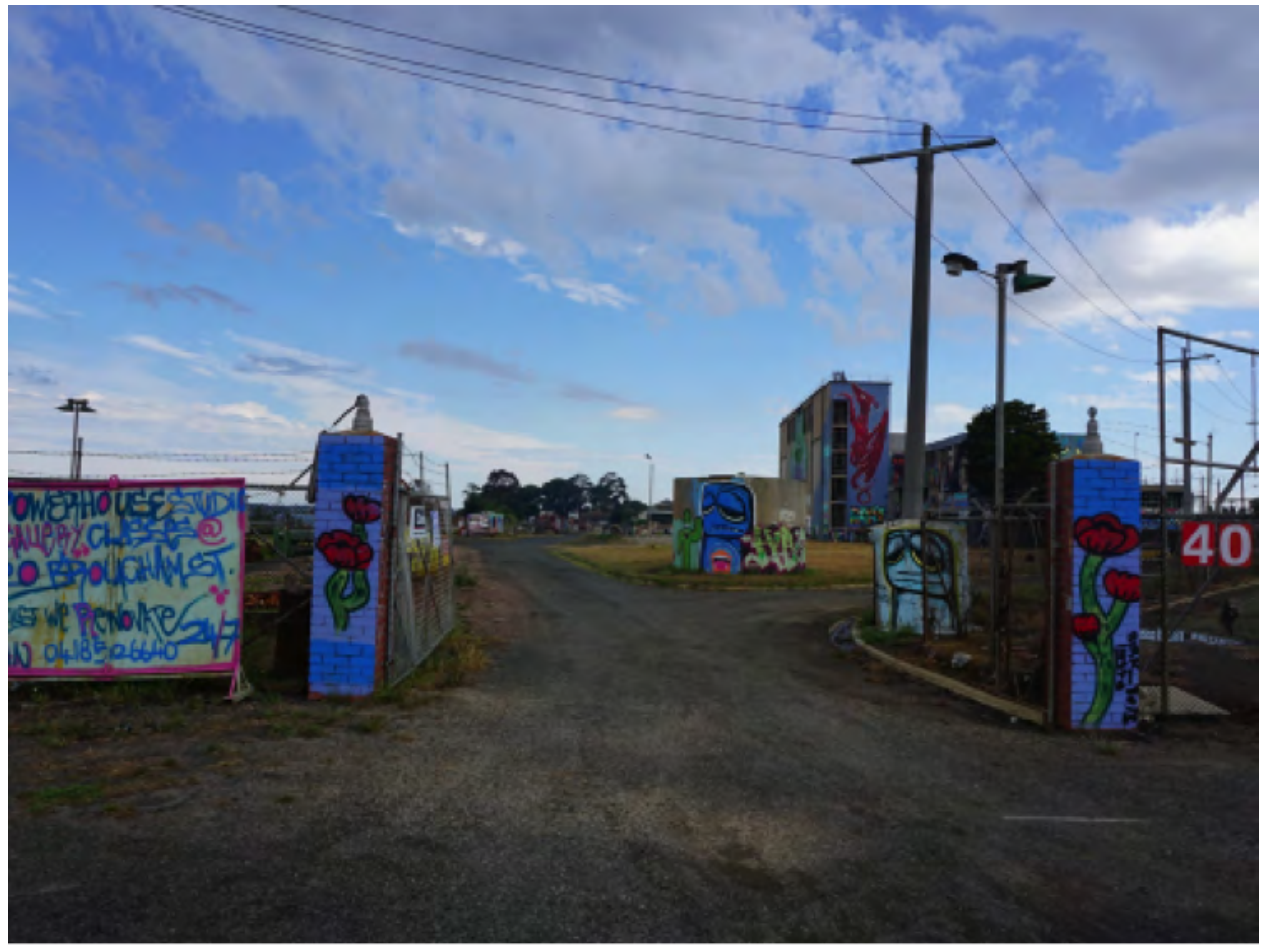

Figure 2: Entrance to the Geelong Power House. Photo: by author, 2015

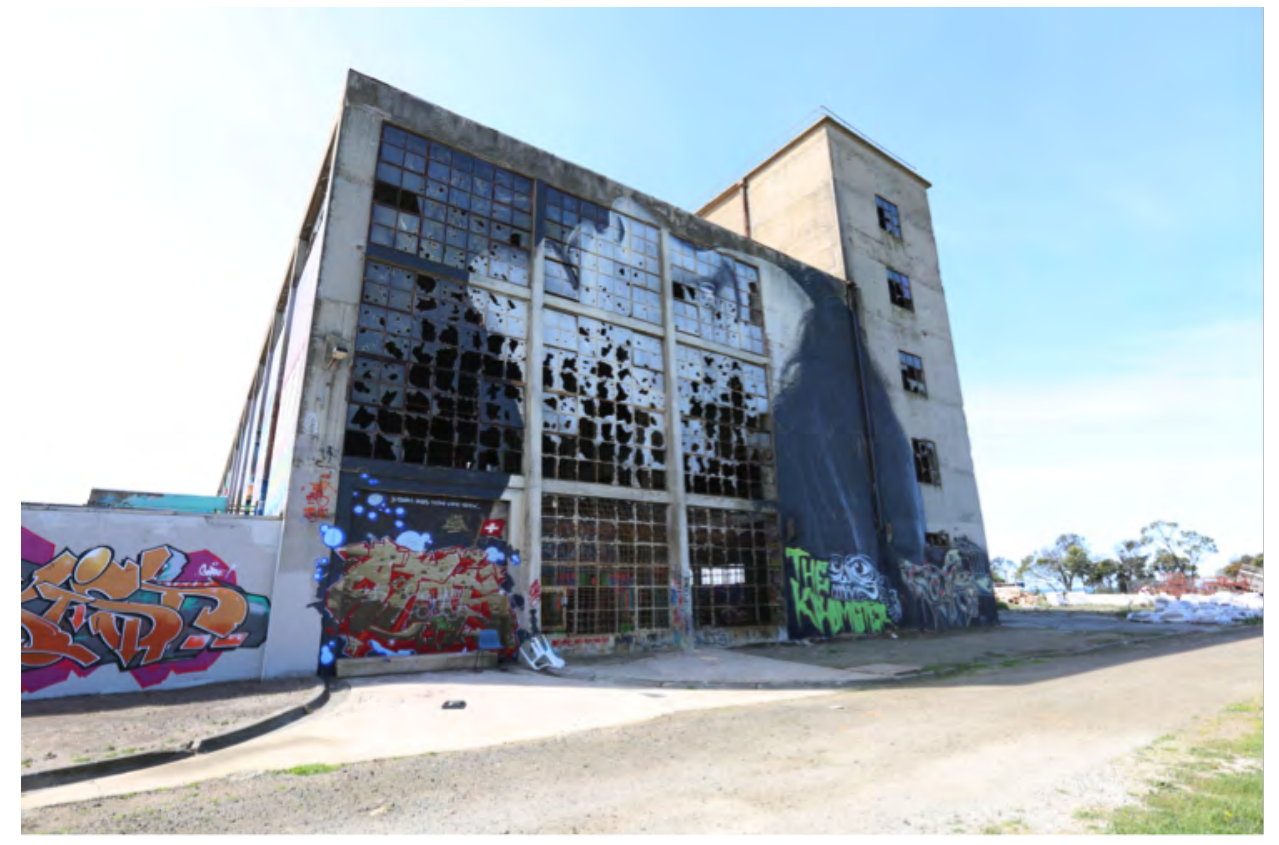

Figure 3: Rone, Broken Window Theory. Photo by author, 2015.

from those numerical narratives of disadvantage in the media? Does this street art provide a new tonality (Manovic 2016) that informs a visual literacy that moves the audience to the desire for 'relatedness' through intercultural understanding?

Martin (2008, p. 28), who is of the Noonuccal, Quandamoopah and the Bidjara peoples states 'to know who you are in relatedness is the ultimate premise of Aboriginal worldview because this is the formation of identity'. Does this enactment of relatedness by the artists reflect a movement within street art operate as interventions against the State regarding in- 
equality towards Indigenous people in Australia? In the act of viewing, photographing and uploading these Indigenous political narratives onto Instagram or Facebook narrow the 'us and them' (Biesta 2012; Said 1978) divide? If so, what are the possibilities of unmediated learning encounters in terms of assembling a new postcolonial receptivity and how is this different from traditional sites for public pedagogy, such as the museum?

\section{Contact Zone 2: Museums}

When examining contact zones there is a notable difference on how one experiences space and how knowledge is produced for the audience. Museums produce knowledge that are assembled within the colonial archive. The rules of presenting knowledge are set within established cultural norms within cultural institutions (Bourdieu 1977, p. 72 cited in Freishtat \& Sandlin 2010 p. 516). Material culture from Indigenous communities have historically been set within a localised section within the museum (and or gallery), rather than integrated throughout the museum.

The Aboriginal gallery section in the South Australian museum, for example, displays material culture from various cultural and linguistically diverse groups within South Australia, such as the Ngarrindjeri people from the Coorong, Lower lakes and Murray River and Kaurna people of the Adelaide plains. Does the use of the past tense in the descriptions of the material culture, the authorial voice of the anthropologist, coupled with the construction of the display cabinets and absence of names of the images of Indigenous peoples represented, shape meaning?

Gough (1977) states it is the curatorial voice that shapes the reading of the images as of the past, rather than as a living culture. This dimmed educative space shapes learning through navigating the viewer through established methods of display common to museum practices around the world. There is a significant shift towards representing Indigenous cultures as living and enduring, such as the Bunjilaka Aboriginal Cultural Centre at Melbourne Museum that works in collaboration with Indigenous community members. However, Boast (2011) argues that regardless, museums as contact zones, remain problematic, particularly when museums represent their inter-cultural exchanges as neutral. Bennet (1998) and Boast (2011) maintain that the inherent power relations of museums sit within governmentality where 'might' wins in any negotiation and thereby asymmetrical relations of power remain entrenched.

The point of interest in this paper is how intercultural understanding of Indigenous and non-Indigenous content and knowledge are made manifest in these complex contact zones. When there is an intractable power relation mediated by governmentality (Foucault 1991) museums as contact zones remain trapped by their colonial heritage and routinely reproduce manifestations of the 'Indigenous other'. However, do technologically mediated spaces offer hope within its ephemeral, un-curated and dynamic representational field to overturn the play of binaries?

\section{Contact Zone 3: Technologically Mediated Spaces: Instagram}

In most western museums learners furtively observe the curated material culture presented as their learning experience. Generally, taking photos in these spaces is banned. Conversely, in the Geelong Powerhouse the audience is free to wander, takes photos, post them on Instagram or Facebook to share their experience and interact with other net users. This interactive engagement is a public pedagogy as it 'becomes a place of enculturation into the logic of personalization' (Luke 2005, p. 6 cited in Freishtat \& Sandlin 2010, p. 509) where one's 
identity is marked by the selection of images chosen personally. Agency to choose images that reflects self becomes an opportunity for 'a pedagogy capable of building new political communities and drawing attention to anti-democratic structures throughout the broader society' (Giroux 2016).

Grossman (2006) has defined the internet as 'the new digital democracy' (cited in Han 2010 p.201). Have new intercultural understandings of Indigenous issues emerged from Instagram? Adnate currently has a following of $57.2 \mathrm{k}$ and his audience photograph and upload his hand at the Geelong powerhouse and his faces of Aboriginal children pasted on buildings across diverse landscapes, including sheds in the Kimberley where he worked with Indigenous youth on a Hip Hop Project (ABC news, n.d.).

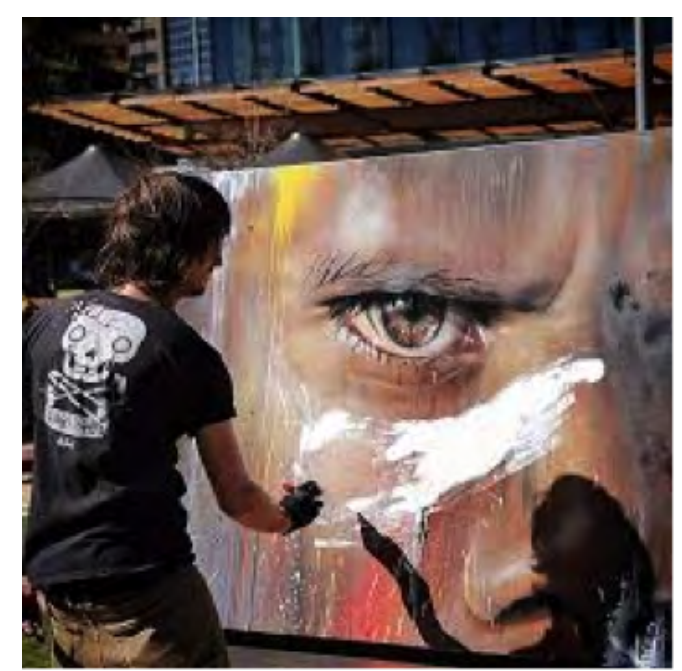

Figure 4: Adnate at work. Photo: Jam project, 2015.

Instagram is a site for observing and selecting images that one is interested in and thereby creates identity markers that the individual constructs. It also contains a range of semiotic elements that have to be read, therefore informs visual and digital literacy. Whilst there are caveats regarding Instagram and the audience/follower, the contact zone remains useful for 'charting broad cultural preferences' (Honig \& MacDowall, 2016) and for reading new trends in digital and visual literacy (Manovic 2016).

The affordances of visual literacy are instantaneous accounts of experience. Manovic (2016) argues there is new poetic design emerging from this practice of photography. He states that the 'best images created by young Instagrammers practice something we can also call 'poetic design' (referencing here 'poetic realism' movement in cinema, minus the narratives)' (Manovic 2016).

Moreover, the affordances of digital literacy include historical recount that can be packaged as a genre. It is visually orientated text, it provides an information report of 'self' engaging in an experience; it is immediate and engages an audience. In this future orientated and spontaneous interactive multi-modal platform exchanges take place. The mode of the text is visual, written and digital. There is a materiality that emerges through the digital image and the accompanying script provides the context. Through this offering and sharing of experience, others can critique and engage with the script.

Urbanmonk's paste up the Aboriginal children, for example, has an extensive script offering a new reading of the failure of the state to deal with Indigenous human rights. His challenging self-critique of his work regarding representations and Indigenous protocols is worth examining in the following (see Fig 1): 
Speaking of low self esteem, a photo someone took of these two paste ups...got about 135 likes on the Powerhouse Instagram Feed. And while it's nice to be noticed, my primary drive in doing these works is to communicate something about the ongoing, largely ignored, suppressed, continually swept under the cultural carpet of Australia's societal fabric fact... the systematic oppression of indigenous people and the dismantling of their identity. An old, but highly contemporary truth.

There's inner conflict about these drawings. A conflict that has gone on for more than a year. They are drawings I have done of deceased aboriginal people. Which is highly offensive to $A b-$ original spirituality. In a sense, I have like so many other white people, potentially walked all over their identity and spirituality by creating these works. Yet I haven't intended this. I really haven't. I've wrestled with the ethics. These are Real People. Children, who lived in Victoria, and had their photo's recorded by white people in the 1860's.

At the time of their recording, they were probably seen as an anthropological record. Like exhibits of extinct fauna. The prevalent attitude of white colonists of the time was that indigenous culture and life was dying. Doomed by manifest destiny of the superior white man to become nothing more than an ethnographic record. Well, these images are so much more than that. And we know now, of course, the tenacious nature of indigenous identity in the face of our bloody minded (and handed) attempts to clear it like the land for profitable crops and livestock.

Right or wrong, maybe both, I have attempted to communicate something more than just a cool picture. (or have I?). There's a story behind these children's eyes, faces, posture, clothing, that perhaps isn't immediately apparent when you snap something for your Instagram feed, yet if you look, or reflect deeper, is very confronting and loaded with meaning. It's communicating a glimpse of that that is my intention...If I failed, I hope I am failing upwards. Urbanmonk (JMC, Josh McCrimmon)

This is political intervention that challenges the State's policy on the Stolen Generation and an enactment of receptivity. It is a narrative that moves towards educative practice in a public space, yet, the past-ups of Indigenous children moves into dangerous territory. Whilst his intent is to comment on the failure of the State to address dispossession and the Stolen generation, without context it may re-enforce the very thing he attempts to deconstruct. In this sense 'public pedagogy scrutinizes the educational process involved when issues and interest are made "public" (Schuermans et al. 2012, p. 677) despite his refreshing honesty of 'failing upwards'. The unpredictability of Instagram followers cannot guarantee that his message is read politically, if at all. However, arguably it is the 'failing upwards' that reveals the very place where the majority of non-Indigenous people should move towards as the alternative to public erasure of these narratives.

Contrast this work to Blak Douglas aka Adam Hill's installation of crates stacked with the word Stolen embedded in the text. This is the same theme regarding the Stolen Generation, but highlights the contemporary situation where more Aboriginal children are removed from their families today than those removed throughout the whole Stolen Generation period (Stopstolengenerations, 2016). Whilst Moreton-Robinson's (1999) contests the ethics of non-Indigenous artists representing Indigenous issues there is something at play in the field of representation that offers hope. Artists, such as Reko Rennie's work on sovereignty (as per image below) and Blak Douglas' work on the Stolen Generation highlight a standpoint that cannot be usurped, but Urbanmonk's and Adnate's work contribute to the debate by offering the audience an educative address on postcolonial receptivity.

Does the work of non-Indigenous street artist such as Urbanmonk that 'fail upwards' lead us out of the intractable binds of otherness within representational fields when located within the cyber scape of Instagram that is shared with Indigenous street artists, such as 


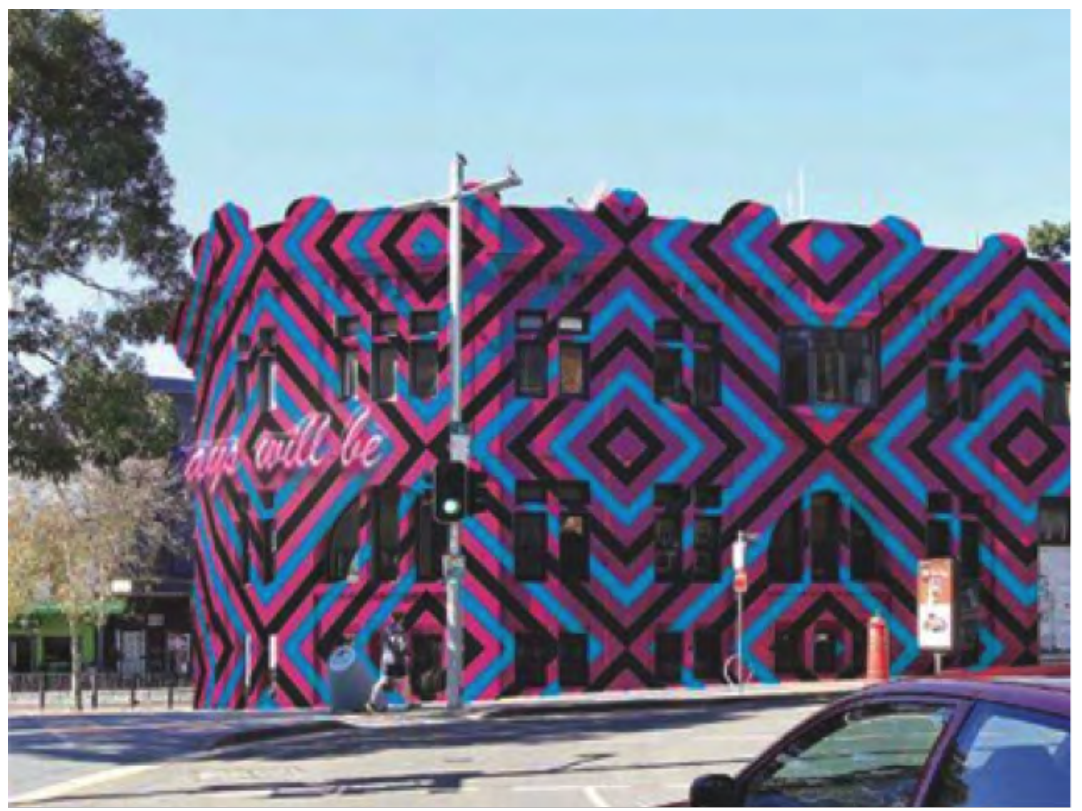

Figure 5: Reko Rennie, Always Was Always Will Be. Photo: Aboriginal Art Directory, 2012.

Reko Rennie and Blak Douglas? Do tech mediated sites offer hope in the contact zone of multi-modality where images share the representational field more democratically? Is this the nexus of representation and agency that works towards a shift in power/knowledge/control and ownership of knowledge production? Whilst the narratives and their standpoints vary, the fight for justice is shared and thereby new allegiances form that work towards a renewed vision of hybridity.

\section{Conclusion}

This paper has explored the representational field of Indigenous narratives mediated within contact zones and the emergence of new intercultural understandings. Examining curated, semi and un-curated contact zones has revealed how these sites contain risks, as well as possibilities for public pedagogy. The paper focused on how curated educational institutions freeze Indigenous art and cultural identity as a result of the limitations of the museum as a contact zone.

The semi-curated space of the Geelong Powerhouse offers an alternate educational experience through an embodied learning encounter that led to an exploration of the parameters of intercultural understanding within contact zones. As a site for public pedagogy Instagram further extends this learning encounter and moves it towards a convergence of Indigenous and non-Indigenous texts that are not demarcated by difference, but instead democratised by the same bandwidth.

Reko Rennie, Blak Douglas, Urbanmonk and Adnates' work is shared with a global audience within the democratic cyber field. These works offer opportunities to 'scale up' meaningful micro-public encounters to a new notion of citizenship which respects difference' (Schuermans et al. 2012). Learning experiences scaffold on emergent visual and digital texts that inform a literacy that offers hope for intercultural understandings of Indigenous political narratives. Whilst running the 'risk' of 'romanticisation' (Schuermans et al. 2012, p. 676), Instagram offers a new tonality (Manovic 2016) that may reflect an emergent but unchartered postcolonial receptivity within the genre of street art. 


\section{Acknowledgement}

I would like to thank Dr. Ruth Fazakerley for her thoughts and contributions towards this paper.

\section{References}

ABC News 2015, 'Giant Portraits draw attention to indigenous issues', viewed 7 December 2015, <http://www.abc.net.au/news/2016-06-15/giant-portraits-draw-attention-toindigenous-issues/7513272>.

Aboriginal Art Directory 2012, 'Reko Rennie, Always Was Always Will Be', viewed 6 November 2015, <http://news.aboriginalartdirectory.com/2012/09/an-aboriginal-artistwhose-work.php>.

Askins, K \& Pain R 2011, 'Contact zones: participation, materiality and the messiness of interaction', Environment and Planning D: Society and Space, vol. 29, no. 5, pp. 803-821.

Bennett, T 1998, Culture: A Reformer's Science, Sage, London.

Biesta, G 2012, 'Becoming public: public pedagogy, citizenship and the public sphere', Social \& Cultural Geography, vol. 13, no. 7, pp. 683-697.

Bignall, S \& MacGill, B 2016, 'Postcolonial Receptivity: Learning to Listen to Indigenous Pedagogies of Care', Educational Philosophy and Theory, Special Issue, in press.

Boast, R 2011, 'Neocolonial collaboration: Museum as Contact Zone Revisited', Museum Anthropology, vol. 34, no. 1, pp. 56-70.

Burdick, J \& Sandlin, J 2013, 'Learning, Becoming, and the Unknowable: Conceptualizations, Mechanisms, and Process in Public Pedagogy Literature', Curriculum Inquiry, vol. 43, no. 1, pp. 142-177.

Clifford, J 1997, Museums as Contact Zones Routes: travel and translation in the late twentieth century, University of California Press, Berkeley.

Foucault, M 1991, 'Governmentality', trans. R Braidotti, in G Burchell, C Gordon and P Miller (eds), The Foucault Effect: Studies in Governmentality, pp. 87-104, University of Chicago Press, Chicago.

Freishstat, R \& Sandlin, J 2010, 'Shaping Youth Discourse About Technology: Technological Colonization, Manifest Destiny, and the Frontier Myth in Facebook's Public Pedagogy', Educational Studies, vol. 46, pp. 503-523.

Geelong Powerhouse 2016, viewed 6 November 2015, <http://powerhousegeelong.com>.

Giroux, H 2016, 'Public Pedagogy and manufactured identities in the age of the selfie culture', Critical/Cultural Studies, Media and Communication Policy, viewed online 15 August 2016.

Goralnik, L, Millenbah, K, Nelson, M \& Thorp, L 2012, 'An environmental pedagogy of care: Emotion, relationships, and experience in higher educaiton ethics learning', Journal of Experiential Education October, vol. 35 no. 3, pp. 412-428.

Gough, J 1997, 'Indigenous Australians in the Australian Museum', Periphery, vol. 31, pp. 10-13.

Han, S 2010, 'Theorizing New Media: Reflexivity, Knowledge, and the Web 2.0', Sociological Inquiry, vol. 80, no. 2, pp. 200-213. 
Hemming, S 1993, 'Camp Coorong-Combining Race Relations and Cultural Education', Social Alternatives, vol. 12, no.1, pp. 37-40.

Honig, C \& MacDowall, L 2016, First Monday, vol. 21, viewed 11 September 2016, <http://firstmonday.org/ojs/index.php/fm/article/view/6810/5600>.

Howitt, R 2001, 'Frontiers, Borders, Edges: liminal challenges to hegemony of exclusion', Australian Geographical Studies, vol. 39, no. 2. pp. 233-245.

Jam Project, 2013, Adnate painting live at the Darling Quarter for Project 5, part of the Art \& About 2013 arts festival in Sydney, viewed 3 March 2016, <https://www.flickr.com/ photos/jam_project/10057834593/in/photostream/>.

Kompridis, N 2013, 'Recognition and Receptivity: Forms of Normative Response, The Lives of the Animals We Are', New Literary History, vol. 44, pp.1-24.

MacGill, B, Matthew, J, Trevorrow, Auntie E, Abdulla, Auntie A \& Rankine, D 2012, 'Ecology, ontology and pedagogy at Camp Coorong', M/C-A Journal of Media and Culture.

Manovic, L 2016, 'Notes on Instagrammism and contemporary cultural identity', viewed 6 February 2016, <http://manovich.net/>.

Moreton-Robinson, A 1999, 'Unmasking whiteness: a Goori Jondal's look at some duggai business', in B McKay (ed.), Unmasking whiteness: race relations and reconciliation, Griffith University Press, Griffith, NSW, pp. 28-36

Pratt, M 1997, 'Arts of the Contact Zone', Mass Culture \& Everyday Life, Peter Gibian (ed.), Routledge, London, pp. 61-72.

Sandlin, J, O’Malley, M \& Burdick, J 2011, 'Mapping the complexity of public pedagogy scholarship 1894-2010', Review of Educational Research, vol. 81, pp. 338-375.

Schuermans, N, Loopmans, M \& Vandenabeele, J 2012, 'Public space, public art and public pedagogy', Social \& Cultural Geography, vol. 13, no. 7. pp. 675-682.

Stopstolengenerations, 2016, viewed 7th August 2016, <http://stopstolengenerations. com.au/15-may-art-installation-condemns-ongoing-stolen-generations-in-lead-up-tonational-sorry-day>.

Urbanmonk, 2015, 'Super market monkey', viewed 7th March 2016, <http:// supermarketmonkey.blogspot.com.au/2015/02/more-at-powerhouse.html>.

\section{About the Author}

Bindi MacGill works as a lecturer and researcher in South Australia. Her primary research interests draw on the fields of Indigenous education, postcolonial theory, visual methodologies and critical race theory. She has published in a broad range of articles concerned with postcolonial receptivity, teaching in the contact zone and feminist art theory.

Dr Belinda MacGill

School of Education

University of South Australia

Belinda.macgill@unisa.edu.au 